\title{
Redes neurais artificiais na estimativa da retenção de água do solo
}

\author{
Artificial neural networks to estimate soil water retention
}

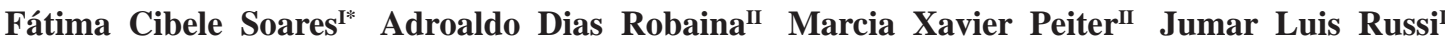 \\ Gisele Aparecida Vivan"II
}

\section{RESUMO}

\begin{abstract}
O trabalho teve como objetivo apresentar uma proposta de metodologia para estimativa da curva de retenção de água, para solos do Estado do Rio Grande do Sul, a partir do uso de redes neurais artificiais. Para o desenvolvimento do trabalho, foi montado um banco de dados com informações disponíveis na literatura, de textura e estrutura dos solos do Estado do Rio Grande do Sul. Para o desenvolvimento das redes, utilizou-se o software Matlab, no qual foram treinadas diferentes arquiteturas, variando os números de neurônios na camada de entrada e camada intermediária. A eficiência das redes foi analisada graficamente pela relação $1: 1$, entre os dados estimados versus os observados, por meio de indicadores estatísticos. Observou-se, a partir dos resultados, que a arquitetura com melhor capacidade preditiva foi: 4-24-7, com classificação do índice de desempenho "ótimo". Assim, pode-se inferir que o uso de redes neurais, para estimativa da curva de retenção de água no solo, é uma ferramenta com alta capacidade preditiva e que trará grande contribuição ao setor agrícola.
\end{abstract}

Palavras-chave: pedofunções, inteligência artificial, umidade do solo, potencial matricial.

\section{ABSTRACT}

The study aims to propose a methodology for estimating the water retention curve for soils of the State of Rio Grande do Sul, by using artificial neural networks. For the development of the research it was assembled a database with information available in the literature, texture and structure of soils of Rio Grande do Sul. The modeling was developed using the software Matlab, where the networks were trained with different architectures, varying the numbers of neurons in the input layer and the hidden layer. The efficiency of the network was analyzed graphically by the ratio 1:1 between the estimated versus the observed data by means of statistical indicators. It was observed from the results that the architecture with best predictive performance was the 4-24-7, with index classification of "great" performance. Thus it can be inferred that the use of neural networks to estimate the water retention curve of the soil is a tool with high predictive ability which will bring great contribution to the agricultural sector.

Key words: pedofunctions, artificial intelligence, soil moisture, matric potential.

\section{INTRODUÇÃO}

O estudo das propriedades físico-hídricas de um solo é de grande importância, visto que afeta preponderadamente o seu uso. Assim sendo, a exploração racional e econômica de áreas irrigadas requer a elaboração de um criterioso dimensionamento e manejo adequado dos sistemas de irrigação e drenagem, levando-se em consideração as alterações das características físico-hídricas do solo, como forma de atender satisfatoriamente as necessidades hídricas das plantas, bem como atenuar a ocorrência da erosão hídrica, presente na grande maioria das áreas irrigadas, devido ao não conhecimento da capacidade de retenção de água dos solos.

Devido à importância da água no desenvolvimento das plantas e suas implicações em várias propriedades do solo, a determinação do teor de água no solo sempre foi de grande interesse, tanto no aspecto científico como no econômico.

\footnotetext{
'Universidade Federal do Pampa (Unipampa), Campus Alegrete, 97546-550, Alegrete, RS, Brasil. E-mail: fatimasoares@unipampa.edu.br. *Autor para correspondência.

IIDepartamento de Engenharia Rural, Centro de Ciências Rurais (CCR), Universidade Federal de Santa Maria (UFSM), Santa Maria, RS, Brasil.

IIIInstituto Federal de Educação, Ciência e Tecnologia Sul-Rio-Grandense (IFSul), Campus Bagé. Bagé, RS, Brasil. Recebido 24.06.13 Aprovado 31.08.13 Devolvido pelo autor 29.11.13 CR-2013-0252.R1
} 
Desse modo, um dos elementos que pode servir de auxílio ao produtor no manejo da irrigação é a determinação da curva de retenção de água do solo, que representa a relação entre o teor de água e a energia com a qual ela está retida no solo. Esse conhecimento é essencial no estudo das relações solo-água-planta. Para DALMAGO et al. (2009), a capacidade de um solo, em armazenar água para o crescimento e desenvolvimento das plantas, está diretamente relacionado a esse atributo físico-hídrico.

A retenção de água no solo é característica específica de cada solo, sendo resultado da ação conjunta e complexa de vários fatores, como o teor e mineralogia da fração argila, teor de matéria orgânica, estrutura, densidade do solo, dentre outros (FREITAS et al., 2004). No entanto, constitui uma propriedade de difícil caracterização, tanto pelo tempo que se consome nas análises, quanto pela intrínseca modificação da amostra, devido à histerese. Sua determinação pode ser efetuada a campo (in situ), por meio de técnicas tradicionais de laboratório, ou através de métodos indiretos, os quais utilizam dados taxonômicos simples para a estimativa da capacidade de retenção da água nos solos (SILVA \& AZEVEDO, 2002). Dentre esses métodos indiretos, destacamse as funções de pedotransferência (FPT), as quais descrevem equações que expressam dependências da retenção da água com elementos básicos disponíveis em levantamentos de solos.

Várias são as técnicas para geração das FPTs, porém a grande maioria delas, muitas vezes, devido à complexidade do elemento de solo analisado, aliado ao pouco conhecimento de lógica matemática, levam a sua geração por simples uso de equações lineares de regressão múltipla (JANA et al., 2007). Porém, estudos realizados por CHAGAS et al. (2007) mostraram que os resultados obtidos por FPTs geradas por redes neurais artificiais são frequentemente melhores do que aquelas obtidas pelos métodos tradicionais. De acordo com BRAGA et al. (2007), redes neurais são, por vezes, descritas como funções aproximadoras universais, uma vez que podem "aprender" a aproximar qualquer função não-linear contínua.

De acordo com BRAGA et al. (2007), as Redes Neurais Artificiais (RNAs) podem ser usadas como ferramentas para geração de FPTs. Sua capacidade de aprendizado, para diferentes variáveis de entrada, torna-as capazes de resolver problemas muito complexos em diversas áreas do conhecimento. Para BRAGA et al. (2007), o desenvolvimento de uma RNA consiste em determinar sua arquitetura, isto é, os números de camadas e de neurônios em cada camada, bem como ajustar seus parâmetros livres, fase esta conhecida como treinamento. A arquitetura varia de acordo com a complexidade do problema e não pode ser definida antes do treinamento, constituindo uma procura baseada em tentativas e erros.

Diante do exposto, o aprimoramento das técnicas de investigação dos elementos de solos, aliado à introdução de novos conceitos e metodologias, tais como a inteligência artificial e a simulação computacional, poderão, em muito, auxiliar os pesquisadores no entendimento dos processos que ocorrem no interior dos solos. Assim, esse trabalho tem por objetivo apresentar uma proposta de metodologia para estimativa da curva de retenção de água, para solos do Estado do Rio Grande do Sul, a partir do uso de redes neurais artificiais.

\section{MATERIAL E MÉTODOS}

Para treinamento das RNAs, foi organizado um conjunto de dados, a partir do levantamento de informações das características físico-hídricas, de solos do Estado do Rio Grande do Sul. Os dados foram extraídos de trabalhos científicos, referentes à dinâmica de água em solos agrícolas, como dissertações e teses.

Foram coletados dados de retenção de água no solo, que possuem informações de unidade volumétrica a vários potenciais matriciais ou parâmetros de ajuste da curva de retenção de água no solo, que permitisse obter valores de unidade, além de teores de areia, silte, argila, matéria orgânica, densidade do solo, densidade de partículas e porosidade total. O banco de dados foi resultado da junção de informações obtidas nos trabalhos dos seguintes autores: BARCELOS (1996); ROJAS (1998); KLEIN (1998); PERAZA (2003); BRANDT (2005); NUNES (2006); UHDE (2009); BRANDT (2009); KUNZ (2009); COLLARES (2005); KAISER (2010); MENTGES (2010). O banco de dados criado com as informações disponíveis na literatura encontra-se publicado em SOARES (2013).

Para desenvolvimento das redes MLP (Multi-Layer-Perceptron), foi utilizado o Neural Network Toolbox do software Matlab (versão 7.12.0.635), com algoritmo backpropagation e otimização Levemberg-Marquadt. Para o treinamento das RNAs, foram escolhidas aleatoriamente $70 \%$ das amostras e os 30\% dos dados restantes ficaram para validação destas (NAGAOKA, et al., 2005; BRAGA et al., 2007).

Utilizou-se uma RNA do tipo $\mathrm{n}_{1} ; \mathrm{n}_{2}$; $\mathrm{n}_{3} ; \mathrm{n}_{4} \rightarrow \mathrm{n}_{5} \rightarrow 7$ : um vetor de entrada com $\mathrm{n}_{1}, \mathrm{n}_{2}, \mathrm{n}_{3}$ 
e $\mathrm{n}_{4}$ variáveis, uma camada intermediária com $\mathrm{n}_{5}$ neurônios artificiais e sete neurônios na camada de saída. Para $\mathrm{n}_{1}$, as variáveis de entrada foram: teores de

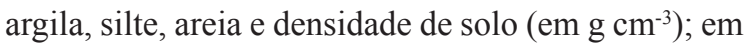
$\mathrm{n}_{2}$, as variáveis de entrada são: teores de argila, silte

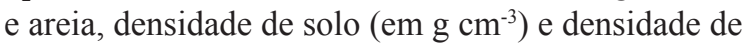
partícula (em $\mathrm{g} \mathrm{cm}^{-3}$ ); para $\mathrm{n}_{3}$, as variáveis de entrada foram: teores de argila, silte e areia, densidade de solo $\left(\mathrm{em} \mathrm{g} \mathrm{cm}^{-3}\right)$, densidade de partícula $\left(\mathrm{em} \mathrm{g} \mathrm{cm}^{-3}\right) \mathrm{e}$ matéria orgânica; em $\mathrm{n}_{4}$, foram: teores de argila, silte

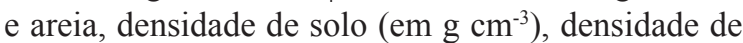

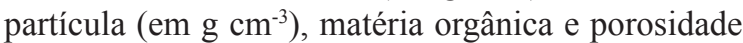
total. Para a camada intermediária $\left(\mathrm{n}_{5}\right)$, foram testados $5 ; 6 ; 7 ; 8 ; 9 ; 10 ; 13 ; 15 ; 18 ; 21 ; 24 ; 27 ; 30 ; 35 ; 40$ e 50 neurônios. No neurônio da camada de saída, empregou-se uma função de ativação linear para fornecer valores de umidade do solo $\left(\mathrm{cm}^{3} \mathrm{~cm}^{-3}\right)$ nos potenciais matriciais de $0,-6,-10,-33,-100,-500$ e $-1500 \mathrm{kPa}$, representada pelos vetores de entrada.

Visando garantir que cada parâmetro de entrada recebesse igual atenção durante o treinamento, aumentando, assim, sua eficiência, tanto os dados de entrada quanto os de saída foram padronizados para o intervalo entre -1 e 1 pela seguinte equação (MATLAB, 2000):

$\mathrm{pn}=\frac{2(\mathrm{p}-\min \mathrm{p})}{(\max \mathrm{p}-\min \mathrm{p})}-1$, em que: pn é o valor

normalizado, adimensional; p, o valor observado; min p, é o valor mínimo da amostra e max p o valor máximo da amostra.

No desenvolvimento da RNA, mantevese constante a função de ativação na camada intermediária (Tangente Hiperbólica sigmoide), a regra de treinamento (Levenberg-Marquardt) e o número de épocas.

Tendo em vista que, no início do treinamento, os parâmetros livres são gerados aleatoriamente e que esses valores iniciais podem influenciar o resultado final do treinamento, a RNA, que representava cada combinação das variáveis, foi treinada 50;200;250; 300; 500;1000; 1500; 2000 vezes. Dentre essas RNAs treinadas, armazenou-se a que apresentou o menor erro relativo médio (ERM), em relação os dados de validação, e menor erro quadrático médio (EQM), em relação os dados de treinamento.

Segundo BRAGA et al. (2007), a escolha da arquitetura de uma rede deve ser feita com cautela, pois uma rede com muitas camadas escondidas ou muitos neurônios nessas camadas pode fornecer excelentes resultados para os dados de treinamento, mas, para os dados de validação, os resultados podem ser totalmente imprecisos (esse problema chama-se overfitting). Dessa forma, escolheu-se como melhor resultado a rede que obteve menor erro relativo médio em relação aos dados de validação. Havendo resultados próximos na escolha da arquitetura, selecionou-se aquela com menor erro quadrático médio em relação os dados de treino, menor número de neurônios na camada escondida e de entrada.

$\mathrm{Na}$ avaliação dos resultados obtidos com a RNA desenvolvida, utilizou-se, além do ERM, o índice de confiança (id), proposto por CAMARGO \& SENTELHAS (1997). Esse índice permite analisar conjuntamente a precisão e a exatidão dos resultados obtidos, sendo calculado pelo produto do coeficiente de correlação (r) e do índice de concordância (c), proposto por WILLMOTT (1981).

\section{RESULTADOS E DISCUSSÃO}

Através dos valores do erro quadrático médio das amostras de treinamento e erro relativo médio das amostras de validação, para os diferentes números de neurônios na camada de entrada e camada escondida, apresentados na tabela 1, observa-se que, para ambas as arquiteturas treinadas, os valores de erro, tanto quadrático médio quanto relativo médio, apresentaram-se baixos. Assim, não necessariamente o aumento do número de neurônios na camada intermediária e número de variáveis na camada de entrada corresponderam aos menores valores para os erros. MACIEL et al. (2012) observaram, em seu estudo com redes neurais, múltiplas camadas que, aumentavam a complexidade da rede com o aumento do número de neurônios na camada intermediária, mas seu desempenho declinava.

Nota-se que as arquiteturas com o número de neurônios na camada de entrada igual a 6 apresentaram uma maior tendência de proporcionar valores de erro relativo médio menores, enquanto as redes com 5 neurônios na camada de entrada apresentaram menores valores para o erro quadrático médio. No entanto, as demais arquiteturas, treinadas, também apresentaram valores baixos para os erros calculados, porém com menor expressividade.

Observou-se ainda que o aumento do número de neurônios na camada escondida não proporcionou uma redução expressiva do erro relativo médio, e que a redução desse erro ocorre, mas expressivamente com o aumento do número de variáveis na camada de entrada. Esses resultados corroboram, de forma parcial, PENG \& WEN (1999), que relatam que uma arquitetura com erro mínimo se atinge com o aumento do número de 
Tabela 1 - Erro quadrático médio (EQM) das amostras de treinamento e erro relativo médio (ERM) das amostras de validação, para as diferentes arquiteturas de RNAs treinadas.

\begin{tabular}{|c|c|c|c|c|c|c|c|c|}
\hline \multirow{2}{*}{$\begin{array}{l}\mathrm{N}^{\mathrm{o}} \text { de neurônios na } \\
\text { camada escondida }\end{array}$} & \multicolumn{2}{|c|}{--------4 variáveis---------- } & \multicolumn{2}{|c|}{--------5 variáveis---------- } & \multicolumn{4}{|c|}{---------6 variáveis---------- ----------7 variáveis------- } \\
\hline & EQM & ERM & EQM & ERM & EQM & ERM & EQM & ERM \\
\hline 5 & 0.0036 & 0.2393 & 0.0034 & 0.1752 & 0.0098 & 0.1557 & 0.0027 & 0.1730 \\
\hline 6 & 0.0037 & 0.1857 & 0.0037 & 0.1907 & 0.0087 & 0.1429 & 0.0028 & 0.1796 \\
\hline 7 & 0.0037 & 0.2062 & 0.0034 & 0.1197 & 0.0089 & 0.1305 & 0.0027 & 0.1689 \\
\hline 8 & 0.0038 & 0.2209 & 0.0035 & 0.1911 & 0.0087 & 0.1307 & 0.0027 & 0.1747 \\
\hline 9 & 0.0036 & 0.1899 & 0.0033 & 0.1494 & 0.0088 & 0.1424 & 0.0026 & 0.1637 \\
\hline 10 & 0.0034 & 0.1577 & 0.0033 & 0.1607 & 0.0095 & 0.1426 & 0.0025 & 0.1685 \\
\hline 13 & 0.0034 & 0.2698 & 0.0028 & 0.1774 & 0.0089 & 0.1692 & 0.0026 & 0.1514 \\
\hline 15 & 0.0035 & 0.2699 & 0.0029 & 0.0967 & 0.0094 & 0.1007 & 0.0023 & 0.1697 \\
\hline 18 & 0.0037 & 0.2333 & 0.0030 & 0.1609 & 0.0077 & 0.1295 & 0.0022 & 0.1681 \\
\hline 23 & 0.0033 & 0.1787 & 0.0026 & 0.1578 & 0.0083 & 0.1603 & 0.0023 & 0.1530 \\
\hline 24 & 0.0028 & 0.1328 & 0.0032 & 0.1305 & 0.0083 & 0.1186 & 0.0021 & 0.1554 \\
\hline 27 & 0.0031 & 0.1377 & 0.0027 & 0.1268 & 0.0079 & 0.1267 & 0.0021 & 0.1480 \\
\hline 30 & 0.0038 & 0.1711 & 0.0027 & 0.1842 & 0.0080 & 0.1736 & 0.0023 & 0.1588 \\
\hline 35 & 0.0034 & 0.1317 & 0.0028 & 0.1269 & 0.0080 & 0.1218 & 0.0022 & 0.1759 \\
\hline 40 & 0.0035 & 0.2059 & 0.0028 & 0.2007 & 0.0066 & 0.1311 & 0.0022 & 0.1652 \\
\hline 50 & 0.0030 & 0.2371 & 0.0030 & 0.2009 & 0.0046 & 0.1168 & 0.0021 & 0.1430 \\
\hline
\end{tabular}

neurônios ou com o aumento do número de ciclos de treinamento, até um limite que não apresente problemas de "memorização", que se caracteriza por apresentar baixo erro quadrático médio na amostra de treinamento, mas com tendência de aumento do erro relativo médio na amostra de validação. MACIEL et al. (2012) testaram diferentes arquiteturas de RNA, variando o número de neurônios na camada escondida de um a quinze. Esses autores observaram que a rede composta por seis neurônios na camada intermediária apresentou os melhores resultados.

De acordo com BRAGA et al. (2007), a escolha da arquitetura de uma rede deve ser feita com atenção, pois uma rede com muitas camadas escondidas ou muitos neurônios nessas camadas pode fornecer excelentes resultados para os dados de treinamento, mas, para os dados de validação, os resultados podem ser totalmente imprecisos. Dessa forma, escolheuse como melhor resultado a rede com 4 neurônios na camada de entrada e 24 neurônios na camada escondida, com 7 variáveis de saída $(4 \longrightarrow 24 \rightarrow 7)$, os resultados de validação, para a respectiva rede, são apresentados na figura 1 .

Observa-se que as correlações indicam que, embora a RNA seja mais exata na predição da umidade retida no potencial de $0 \mathrm{kPa}$, ela também apresenta bom ajuste para os demais potenciais, com valores de coeficientes de determinação $\left(\mathrm{r}^{2}\right)$ superiores a 0.70 (Figura 1), uma vez que, segundo GARCIA
(1989), valores de coeficiente de determinação superiores a 0,70 indicam bons ajustes. Porém, esses resultados encontrados discordam de OLIVEIRA et al. (2002), sendo que estes elaboraram funções de pedotransferência, a partir do uso de regressão linear múltipla, para estimar o conteúdo de água nos potenciais de -33 e $-1500 \mathrm{kPa}$, a partir de dados granulométricos e de densidade do solo, para solos do estado de Pernambuco. Estes autores encontraram as melhores correlações para predição da umidade a $-1500 \mathrm{kPa}$, o que reforça a discussão da literatura de que a relação entre a retenção de umidade e a textura dos solos, ao menos até certo ponto, estreita-se, à medida que aumenta a tensão, como foi discutido por ARAÚJO et al. (2003). Talvez a discordância entre os trabalhos deva-se ao modo de modelagem utilizada, uma vez que RNA não apresenta linearidade entre as variáveis preditoras e as preditas.

Os valores dos coeficientes de correlação (r), índice de concordância (c) e classe de desempenho, para as diferentes arquiteturas testadas neste trabalho, em relação aos dados observados, são apresentados na tabela 2. Observa-se que ambos os índices estatísticos apresentaram-se elevados, resultando em índices de desempenho (id) (produto de (r) e (c)) superiores a 0,76 , o que as classifica quanto ao desempenho comparativo como "muito bom" (id entre 0,76 a $0,85)$ e "ótimo" (id $>0,85)$, porém observa-se, a partir da tabela 2, que a RNA com a arquitetura 


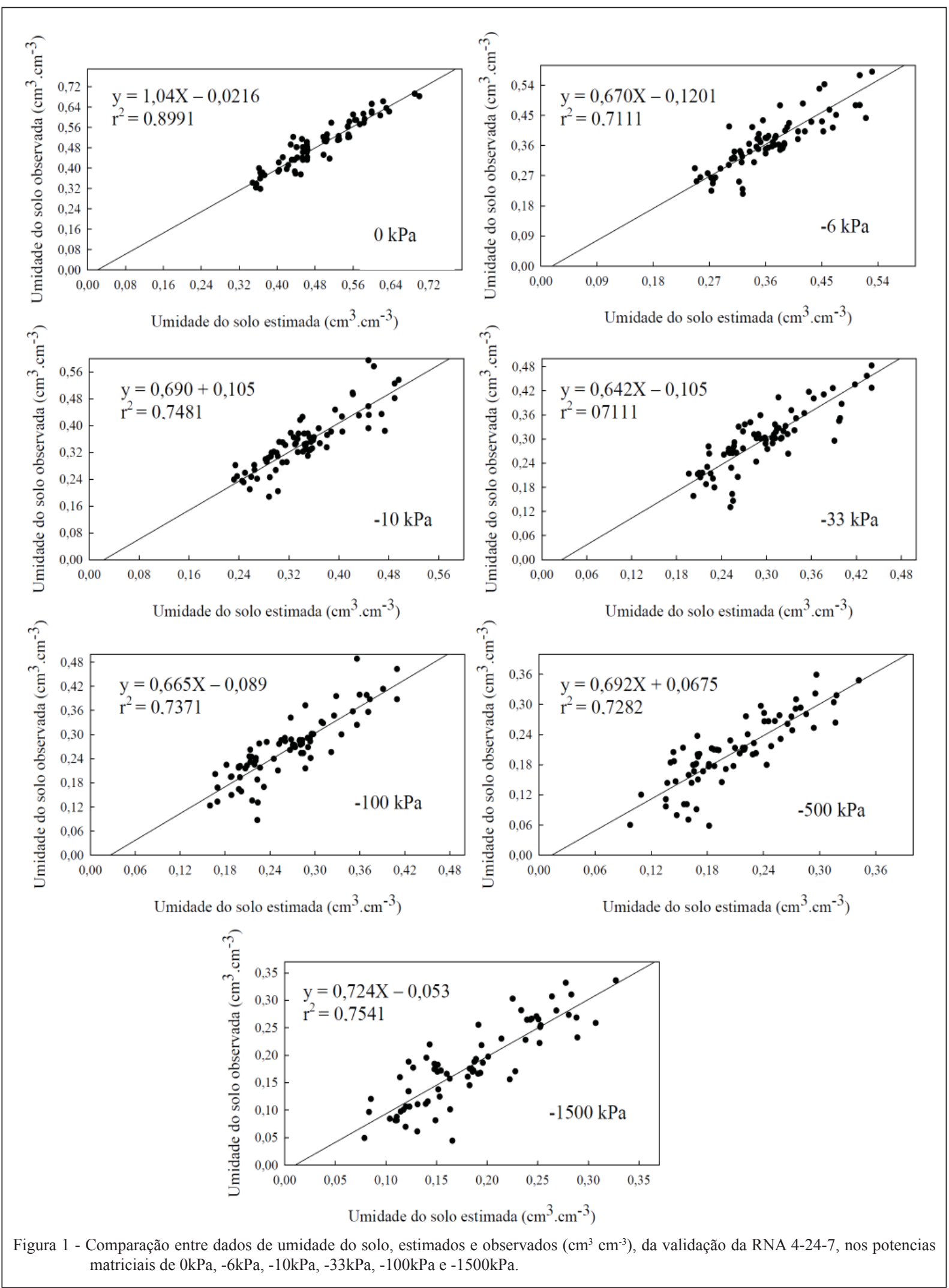

Ciência Rural, v.44, n.2, fev, 2014. 
Tabela 2 - Valores do coeficiente de correlação (r), índice de concordância (c) e da classificação do desempenho (CD) das RNAs em relação aos valores observados, para a umidade do solo em diferentes potenciais.

\begin{tabular}{|c|c|c|c|c|c|c|c|c|c|c|c|c|}
\hline \multirow{2}{*}{ NCE* } & \multicolumn{3}{|c|}{------------4 entradas------------- } & \multicolumn{3}{|c|}{ 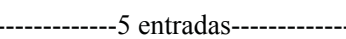 } & \multicolumn{3}{|c|}{-----------6 entradas------------- } & \multicolumn{3}{|c|}{-----------7 entradas---------- } \\
\hline & $\mathrm{r}$ & $\mathrm{c}$ & $\mathrm{CD}$ & $\mathrm{r}$ & $\mathrm{c}$ & $\mathrm{CD}$ & $\mathrm{r}$ & $\mathrm{c}$ & $\mathrm{CD}$ & $\mathrm{r}$ & $\mathrm{c}$ & $\mathrm{CD}$ \\
\hline 5 & 0.9139 & 0.8643 & $\begin{array}{l}\text { muito } \\
\text { bom }\end{array}$ & 0.9269 & 0.8807 & $\begin{array}{l}\text { muito } \\
\text { bom }\end{array}$ & 0.9971 & 0.9945 & ótimo & 0.9328 & 0.8848 & $\begin{array}{l}\text { muito } \\
\text { bom }\end{array}$ \\
\hline 6 & 0.9288 & 0.8830 & $\begin{array}{l}\text { muito } \\
\text { bom }\end{array}$ & 0.9389 & 0.9042 & $\begin{array}{l}\text { muito } \\
\text { bom }\end{array}$ & 0.9974 & 0.9950 & ótimo & 0.9413 & 0.8950 & $\begin{array}{l}\text { muito } \\
\text { bom }\end{array}$ \\
\hline 7 & 0.9145 & 0.8586 & $\begin{array}{l}\text { muito } \\
\text { bom }\end{array}$ & 0.9559 & 0.9211 & ótimo & 0.9975 & 0.9952 & ótimo & 0.9383 & -0.0030 & $\begin{array}{l}\text { muito } \\
\text { bom }\end{array}$ \\
\hline 8 & 0.9204 & 0.8743 & $\begin{array}{l}\text { muito } \\
\text { bom }\end{array}$ & 0.9362 & 0.9129 & ótimo & 0.9978 & 0.9962 & ótimo & 0.9613 & 0.9291 & ótimo \\
\hline 9 & 0.9251 & 0.8779 & $\begin{array}{l}\text { muito } \\
\text { bom }\end{array}$ & 0.9349 & 0.9122 & ótimo & 0.9970 & 0.9945 & ótimo & 0.9328 & 0.9096 & $\begin{array}{l}\text { muito } \\
\text { bom }\end{array}$ \\
\hline 10 & 0.9354 & 0.8975 & $\begin{array}{l}\text { muito } \\
\text { bom }\end{array}$ & 0.9412 & 0.9092 & ótimo & 0.9971 & 0.9947 & ótimo & 0.9328 & 0.9214 & $\begin{array}{l}\text { muito } \\
\text { bom }\end{array}$ \\
\hline 13 & 0.9267 & 0.8882 & $\begin{array}{l}\text { muito } \\
\text { bom }\end{array}$ & 0.9453 & 0.9205 & ótimo & 0.9971 & 0.9945 & ótimo & 0.9356 & 0.8312 & $\begin{array}{l}\text { muito } \\
\text { bom }\end{array}$ \\
\hline 15 & 0.9402 & 0.8930 & $\begin{array}{l}\text { muito } \\
\text { bom }\end{array}$ & 0.9518 & 0.9204 & ótimo & 0.9980 & 0.9963 & ótimo & 0.9552 & 0.8739 & $\begin{array}{l}\text { muito } \\
\text { bom }\end{array}$ \\
\hline 18 & 0.9362 & 0.8891 & $\begin{array}{l}\text { muito } \\
\text { bom }\end{array}$ & 0.9334 & 0.8788 & ótimo & 0.9966 & 0.9937 & ótimo & 0.9596 & 0.8897 & ótimo \\
\hline 23 & 0.9238 & 0.8818 & $\begin{array}{l}\text { muito } \\
\text { bom }\end{array}$ & 0.9433 & 0.9145 & ótimo & 0.9972 & 0.9949 & ótimo & 0.9639 & 0.9322 & ótimo \\
\hline 24 & 0.9638 & 0.9496 & ótimo & 0.9545 & 0.9264 & ótimo & 0.9980 & 0.9964 & ótimo & 0.9328 & 0.9247 & $\begin{array}{l}\text { muito } \\
\text { bom }\end{array}$ \\
\hline 27 & 0.9587 & 0.9337 & ótimo & 0.9455 & 0.9245 & ótimo & 0.9978 & 0.9963 & ótimo & 0.9686 & 0.9435 & ótimo \\
\hline 30 & 0.9418 & 0.8922 & $\begin{array}{l}\text { muito } \\
\text { bom }\end{array}$ & 0.9510 & 0.9236 & ótimo & 0.9978 & 0.9958 & ótimo & 0.9616 & 0.9286 & ótimo \\
\hline 35 & 0.9519 & 0.9385 & ótimo & 0.9677 & 0.9477 & ótimo & 0.9980 & 0.9967 & ótimo & 0.9651 & 0.9357 & ótimo \\
\hline 40 & 0.9458 & 0.9125 & ótimo & 0.9453 & 0.9078 & ótimo & 0.9977 & 0.9960 & ótimo & 0.9328 & 0.9317 & $\begin{array}{l}\text { muito } \\
\text { bom }\end{array}$ \\
\hline 50 & 0.9393 & 0.9004 & $\begin{array}{l}\text { muito } \\
\text { bom }\end{array}$ & 0.9403 & -0.0050 & $\begin{array}{l}\text { muito } \\
\text { bom }\end{array}$ & 0.9966 & 0.9936 & ótimo & 0.9578 & 0.9195 & ótimo \\
\hline
\end{tabular}

*NCE: número de neurônios na camada escondida.

Ciência Rural, v.44, n.2, fev, 2014. 
de $4 \rightarrow 24 \rightarrow 7$ apresentou o menor erro relativo médio, entre os dados observados e estimados, para validação. Portanto, considerando que a respectiva RNA acarretou em menor erro relativo médio, além de maior índice de confiança, pode-se afirmar que ela permitiu melhor estimativa dos valores de umidade em diferentes potencias matriciais. Dessa forma, a RNA desenvolvida pode ser utilizada com satisfatório grau de precisão na predição da curva característica de água no solo, auxiliando, assim, técnicos e agricultores nas estimativas das lâminas de irrigação, proporcionando, deste modo, um melhor planejamento de uso, manejo e conservação dos recursos naturais.

Os resultados corroboram JANA \& MOHANTY (2011) e JANA et al. (2008; 2007). Esses autores, através do uso de RNAs para estimativa de propriedades hidráulicas do solo, observaram que a metodologia apresenta alta capacidade preditiva, além de superar as metodologias padrão de estimativa.

\section{CONCLUSÃO}

A curva característica de água para solos do Estado do Rio Grande do Sul pode ser estimada, com alta capacidade preditiva, a partir do uso de redes neurais artificais com 4 neurônios na camada de entrada (dados texturais e de densidade do solo) e 24 neurônios na camada intermediária. $\mathrm{O}$ uso de redes neurais múltiplas camadas, treinadas com o algoritmo backpropagation, mostrou grande potencial para o desenvolvimento de ferramenta que auxilie o setor agrícola para uma maior otimização dos sistemas irrigados.

\section{REFERÊNCIAS}

ARAÚJO, A.E. et al. Cultivo do algodão irrigado. Campina Grande: Embrapa, 2003. Acesso em: 29 maio 2012. Online. Disponível em: <http://sistemasdeproducao.cnptia.embrapa.br/ FontesHTML/Algodao/AlgodaoIrrigado/solos.htm>.

BARCELOS, A.A. Infiltração de água em um latossolo, sob chuva de alta intensidade, em diferentes sistemas de manejo. 1996. 112f. Dissertação (Mestrado em Ciência do solo) - Curso de Pós-graduação em Ciência do solo, Universidade Federal do Rio Grande do Sul, RS.

BRAGA, A.P. et al. Redes neurais artificiais - Teoria e aplicações. 2.ed. Rio de Janeiro: LTC, 2007. 226p.

BRANDT, A.A. Carregamento estático e dinâmico e sua relação com tensão, deformação e fluxos no solo. 2009. 162f. Tese (Doutorado em Engenharia Agrícola) - Curso de Pós-graduação em Engenharia Agrícola, Universidade Federal de Santa Maria, RS.

BRANDT, A.A. Propriedades mecânicas de solo franco arenoso sob distintos sistemas de preparo, tráfego mecanizado e resíduos vegetais. 2005. 89f. Dissertação (Mestrado em Engenharia Agrícola) - Curso de Pós-graduação em Engenharia Agrícola, Universidade Federal de Santa Maria, RS.

CAMARGO, A.P.; SENTELHAS, P.C. Avaliação do desempenho de diferentes métodos de estimativa da evapotranspiração potencial no Estado de São Paulo, Brasil. Revista Brasileira de Agrometeorologia, v.5, p.89-97, 1997.

CHAGAS, S.C. et al. Utilização de redes neurais artificiais para predição de classes de solo em uma bacia hidrográfica no domínio de mar de morros. In: SIMPÓSIO BRASILEIRO DE SENSORIAMENTO REMOTO, 13., 2007, Florianópolis, SC. Anais... Florianópolis: Instituto Nacional de Pesquisas Espaciais, 2007. p.2421-2428

COLLARES, G.L. Compactação em latossolos e argissolo e relação com parâmetros de solo e planta. 2005. 107f. Tese (Doutorado em Ciência do solo) - Curso de Pós-graduação em Ciência do solo, Universidade Federal de Santa Maria, RS.

DALMAGO, G.A. et al. Retenção e disponibilidade de água às plantas, em solo sob plantio direto e preparo convencional. Revista Brasileira de Engenharia Agrícola e Ambiental, v.13, (Supl.), p.855-864, 2009.

FREITAS, P.S.L. et al. Efeito da cobertura de resíduo da cultura do milho na evaporação da água do solo. Revista Brasileira de Engenharia Agrícola e Ambiental, v.1, p.85-91, 2004.

GARCIA, C.H. Tabelas para classificação do coeficiente de variação. Piracicaba: Instituto de Pesquisas e Estudos Florestais, Escola Superior de Agricultura "Luiz de Queiroz", 1989. 12p. (Circular técnica, 171).

JANA, R.B., MOHANTY, B.P. Enhancing PTFs with remotely sensed data for multi-scale soil water retention estimation. Journal Hydrology, v. 399, p.201-211, 2011. Disponível em: http://vadosezone.tamu.edu/publications/2011 1.pdf. Acesso em: 20 de abril de 2012. doi:10.1016/j.jhydrol.2010.12.043. 2011.

JANA, R.B. et al. Multiscale bayesian neural networks for soil water content estimation, Water Resources Research, v.44, p.1-16, 2008. Disponível em: <http://vadosezone.tamu.edu/ publications/2008_6.pdf>. Acesso em: 20 de abril de 2012.doi: 10.1029/2008WR006879. 2008.

JANA, R.B. et al. Multiscale pedotransfer functions for soil water retention multiscale pedotransfer functions for soil water retention. Vadose zone Journal, v.6, p.868-878, 2007.

KAISER, D.R. Estrutura e água em argissolo sob distintos preparos na cultura do milho. 2010. 151f. Tese (Doutorado em Ciência do Solo) - Curso de Pós-graduação em Ciência do Solo, Universidade Federal de Santa Maria, RS.

KLEIN, V.A. Propriedades físico-hídrico-mecânica de um latossolo roxo, sob diferentes sistemas de uso e manejo. 1998. 150f. Tese (Doutorado em Agronomia) - Curso de Pós-graduação em Solos e nutrição de Plantas, Universidade de São Paulo, SP.

KUNZ, M. Comportamento físico de um latossolo sob integração lavoura-pecuária. 2009. 70f. Dissertação (Mestrado em Engenharia Agrícola) - Curso de Pós-graduação em Engenharia Agrícola, Universidade Federal de Santa Maria, RS.

MACIEL, L. dos S. et al. Apreçamento de opções sobre taxa de câmbio R\$/US\$ negociadas no Brasil: uma comparação entre os 
modelos Black e redes neurais artificiais. Administração, v.47, n.1, p.96-111, 2012

MENTGES, M.I. Implicações do uso do solo nas propriedades físico-hídricas e mecânicas de um argissolo vermelho-amarelo e de um gleissolo háplico. 2010. 108f. Dissertação (Mestrado em Ciência do Solo) - Curso de Pós-graduação em Ciência do Solo, Universidade Federal de Santa Maria, RS.

NUNES, M.C.M. Erosão hídrica em entressulcos de latossolos do Rio Grande do Sul. 2006. 175f. Dissertação (Mestrado em Ciência do Solo) - Curso de Pós-graduação em Ciência do Solo, Universidade Federal do Rio Grande do Sul, RS

OLIVEIRA; L.B. et al. Funções de pedotransferência para predição da umidade retida a potenciais específicos em solos do Estado de Pernambuco. Revista Brasileira de Ciência do Solo, v.26, n.2, p.315-324, 2002.

NAGAOKA, M.E. et al. Um método para estimar densidade de solo utilizando redes neurais artificiais. Energia na Agricultura, v.20, n.4, p.53-68, 2005.

PENG, C.; WEN, X. Recent applications of artificial neural networks in forest resource management: an overview. In: CORTÉ, U.; SÀNCHEZ-MARRÈ, M. (Eds.). environmental decision support systems and artificial intelligence. Menlo Park: AAAI, 1999. p.15-22.
PERAZA, J.E.S. Retenção de água e pedofunções para solos do Rio Grande do Sul. 2003. 117f. Dissertação (Mestrado em Engenharia Agrícola) - Curso de Pós-graduação em Engenharia Agrícola, Universidade Federal de Santa Maria, RS.

ROJAS, C.A.L. Alterações físico-hídricas de um podzólico em função do manejo de solo. 1998. 77f. Dissertação (Mestrado em Ciência do Solo) - Curso de Pós-graduação em Ciência do Solo, Universidade Federal do Rio Grande do Sul, RS.

SILVA, E.M. da; AZEVEDO, J.A. de. Influência do período de centrifugação na curva de retenção de água em solos de Cerrado. Pesquisa Agropecuária Brasileira, v.37, p.1487-1494, 2002.

SOARES, F.C. Uso de diferentes metodologias na geração de funções de pedotransferência para a retenção de água em solos do Rio Grande do Sul. 2013. 200f. Tese (Doutorado em Engenharia Agrícola) - Curso de Pós-graduação em Engenharia Agrícola, Universidade Federal de Santa Maria, RS.

UHDE, S.L.T. Sistema pedológico de um ambiente antropizado da depressão central do RS. 2009. 226f. Tese (Doutorado em Ciência do Solo) - Curso de Pós-graduação em Ciência do Solo, Universidade Federal de Santa Maria, RS.

VEREECKEN, H. et al. Estimating unsaturated hydraulic conductivity from easily measured soil properties. Soil Science, v.149, p.389-403, 1990 .

WILlMOTT, C.J. On the validation of models. Physical Geographic, v.2, p.184-194, 1981. 